\title{
Responsibility in the Use of Medical Information for Research
}

\author{
STATEMENT BY THE MEDICAL RESEARCH COUNCIL
}

British Medical fournal, 1973, 1, 213-216

\section{(1) Introduction}

In its statement on investigations on human subjects ${ }^{1}$ the Council referred to the rapid advance in medical knowledge during the past 50 years due to the combination of the methods of laboratory science with the traditional methods of clinical medicine. A distinction was drawn between procedures undertaken for the benefit of individual patients and those undertaken on patients or healthy subjects solely for the purpose of contributing to medical knowledge; and guidelines were established for the regulation of procedures of the latter kind. The systematic collection and analysis of medical information has always been an important requisite for those doctors, particularly medical officers of health, concerned with the study and control of the health of the whole population rather than the individual patient. Methods of assembling such information have become more advanced in recent years as a result of progress in survey techniques and automatic data processing. At the same time the diseases which are now the most important are not those that were prominent in the past. The consequence is that epidemiological methods which hitherto were resticted chiefly to the study of the infectious diseases are now employed for the investigation of the more complex problems posed by the non-infectious diseases. Just as new ethical problems were raised by the development of advanced technical procedures in clinical investigations so similar problems have emerged over the past three decades in the use of confidential medical information in research, particularly when the investigator is not involved in the care or treatment of the individual concerned.

The Medical Research Council recognizes the importance of such work but considers it appropriate, in order to ensure the continued protection of the private and personal interests of members of the public so successfully achieved in the past, to give guidance on the conduct of investigations involving the transfer of medical information.

Formerly the simplicity of the doctor-patient relationship ensured that information gained in the course of medical practice was not divulged. With increasing specialization it is no longer always practicable for one doctor to be the sole confidant of the patient, and it is implicitly understood that this confidence may be extended both to other doctors and to non-medical staff involved in the patient's care.

The control of epidemics of infectious disease was achieved in part through the notification of its onset in individual patients by family doctors to the medical officer of health. Similarly the control of non-infectious diseases may be assisted by the transfer of medical information between doctors. The origins of many of these non-infectious diseases may lie in early life, their evolution is slow and insidious, and the relation between cause and effect is often obscure and complex. The changing social habits and conditions of life in a congested urban community, together with changes in industrial processes, continually create new health hazards, such as the toxic hazards of food additives, combustion of fuels on a new scale or of a new type, and environmental pollution. Advances in the production of new powerful therapeutic and prophylactic agents have created a need not only to assess their effectiveness in comparison with existing drugs or forms of treatment but also to maintain a continued watch for the development of adverse reactions.

These new problems have necessitated new research techniques, which in turn have led to new methods for the protection of the community's health. Studies involving comparison of the characteristics, ways of life, and environmental circumstances of affected and unaffected individuals have helped to isolate causal agents and personal factors associated 
with especial risk. Such studies have uncovered important determinants of disease such as cigarette smoking, air pollution due to the inefficient combustion of coal, and the characteristics of physique that portend serious heart disease. The collection of personal medical data was also of crucial value in special investigations of maternal deaths, perinatal mortality, and child health, while cancer registration has provided essential information on the natural history of malignant disease. The use of similar methods holds promise for the future prevention of congenital malformations and inborn metabolic diseases, for the development of new methods of monitoring and presymptomatic screening, and for the creation of more effective methods for controlling and alleviating the disabilities that accompany the ageing process.

In much of this work it is essential for the data to relate to identified individuals so that information recorded at different times and places can be collated. It is this collection and handling of medical information relating to identified individuals by those other than their personal doctors that makes it imperative for research workers to respect confidentiality.

\section{(2) Medical Records}

Medical records comprise all recorded observations relating to identifiable individuals made in the context of (i) health and medical care; (ii) medical research; (iii) other circumstances in which information is given to a doctor in his professional capacity; (iv) other situations in wbich medically relevant information is recorded such as birth notification, claim for sickness benefit, examinations in connexion with life assurance, etc. These records will also on occasion include data which are confidential but which are not strictly medical. In the present context medical records are not considered to include nominal lists such as those maintained by executive councils.

There is no necessary difference in content between conventional written records and data in comouter systems. In computer systems speed of access to records is much greater than in conventional systems, ease of communication within and among systems is enhanced, and the physical bulk of the records is reduced. In most computerized systems the plain language content of records is small, and casual or unauthorized access is correspondingly difficult. Computers may render medical record systems even more useful in the management of patient care, health services management, and research, but clearly they involve a special degree of responsibility for those who control them.

\section{(3) Principles Underlying Responsibility}

The Council considers that, subiect to certain safeguards, medical information obtained about identified individual patients should continue to be made available without their explicit consent for the purnoses of medical research. The necessary safeguards are as follows.

(i) All medical information that can be related to an identified individual should be treated as confidential and should be communicated only to medical research workers who are engaged in investigations in the interests of the health of the community and only if, in the opinion of the medical practitioner holding that information, such communication will not harm the subject's interests.

(ii) The transfer of confidential medical information between members of the medical profession is, as already noted, an accepted practice in certain con'exts. This practice is largely based on the fact that those whose names are on the Register of the General Medical Council are fully accountable to that body for their ethical conduct. Although a number of professional organizations have laid down ethical codes for their members, the lack of a similar legally established accountability raises special considerations in the case of research workers who are not on the Medical Register despite their considerable contribution to medical research. The Council therefore considers:

that for the time being non-medically qualified research workers and assistants should have access to such information only $(a)$ when working in collaboration with a medically qualified worker who will take responsibility for con-

fidentiality; or (b), where there is no medically qualified collaborator, after the approval of the Standing Committee referred to in the appendix (below) has been obtained.

(iii) Where the personal collaboration of the subject or patient is requested, the right of those approached to refuse it without giving a reason must always be respected.

(iv) The results of investigations should never be presented in such a way that identification of individual subjects might be possible.

The overriding consideration must always be that no harm or distress will ensue for the individual and his family, and that the doctor-patient relationship will in no way be impaired. For this reason the Council has established for its own purposes a committee to advise both its staff and supported workers who are custodians of confidential data and medical research workers, details of which are referred to in the appendix.

\section{(4) The Conduct of Research}

Research involving the collection of medical information about groups of the population may be conducted in a number of ways. These require the participation of multidisciplinary research teams, the members of which must be aware of, and respect, the confidential nature of the information being collected.

\section{(i) SURVEYS OF THE APPARENTLY WELL POPULATION}

Surveys may be undertaken on "total" populations or on samples selected from public records such as the electoral roll. It is considered that direct approaches (for example, by postal questionnaire or visit interview) to apparently well subjects in the general population selected in this way do not require approval or consent of any local medical body or individual. Whenever practicable, however, workers should consult with the local medical committee and inform practitioners about their proposed studies. As already noted, the right of any subject to decline to take part in such a survey must always be respected.

Where approaches involve visiting subjects at home, it is generally desirable that some advance notice be given, and it is imperative that field staff should be provided with means for ready personal identification including a reference telephone number. In some circumstances it may be appropriate to inform local police.

Surveys may on occasion involve the physical examination or laboratory investigation of subjects. In these ci. umstances the true consent* of subjects must always be obtained before any such examination is undertaken. Where clinical examination is involved, advance information about the survey for local practitioners is of special importance.

Research workers should always seek the permission of subjects to send to their doctors any relevant test results or abnormal findings that may be detected in the course of such surveys. The wishes of the subjects must be respected. If findings suggestive of serious disease are made, a subject who has not given permission for the transfer of information

"Defined by the Council as "consent freely given with proper understanding of the nature and consequences of what is proposed." 
to his doctor should be urged to seek further medical advice so that a more comprehensive examination can be carried out. In the interests of safeguarding the doctor-patient relationship, research workers should avoid expressing opinions about findings to subjects or in any way committing the patient's doctor to a particular course of action.

\section{(ii) RESEARCH BASED WHOLLY ON MEDICAL RECORDS}

Some research involves no more than the examination and analysis of existing medical records. When the records are held by the doctor responsible for making them, the principles covering such inquiries are covered under section 3 . There are, however, situations where the relevant records or information as to where they are available may be held in centres controlled by other persons. These are referred to in section 5 .

\section{(iii) RESEARCH REQUIRING ACCESS TO SUBJECTS IDENTIFIED FROM MEDICAL RECORDS}

Research workers may wish to approach individuals identified from medical records in order to seek additional information. Such an approach to the individual concerned is possible only because an exchange of confidential medical information has taken place, and the consent of the subject's medical adviser must be obtained. When such consent is given, the subject may be approached directly by the research worker, unless the subject's doctor prefers to make the initial approach himself. If doubts arise about a particular project, the proposal can be referred to the standing committee.

(iv) FOLLOW-UP OF INDIVIDUALS EXPOSED TO POTENTIALLY HARMFUL ENVIRONMENTS

In certain circumstances it is in the public interest and in the interest of the individuals concerned that a follow-up survey be carried out without the prior knowledge or consent of the subjects. For instance, such a situation may arise when identifiable individuals have been exposed to a toxic substance or other potential hazard but the evidence is not strong enough to justify raising their fears by informing them of it.

An obvious example would be in relation to exposure to industrial processes. In such a case prior discussion should take place in confidence with representatives of the workers involved and with management. An undertaking should be given that results will be made known immediately there is firm evidence of the existence of a hazard.

Other examples arise in relation to the potential long-term consequences of earlier morbidity or exposure to diagnostic, prophylactic, or therapeutic procedures. In such cases the individuals to be examined might be identified from medical records as well as followed up by means of them. The ethical position will usually have to be examined on an ad hoc basis.

\section{(v) RESEARCH REQUIRING ACCESS TO RELATIVES OF PATIENTS}

In studies involving the genetic or familial aspects of disease, research workers may wish to interview the relatives of patients or subjects. Whenever possible, permission to approach relatives should be obtained from the patient. The reason for this approach, and the method by which the relative has been identified, should be immediately explained in such a way as to minimize possible anxiety. (vi) RESEARCH INVOLVING MINORS AND THE MENTALLY SUBNORMAL OR DISORDERED

The Council's statement "Responsibility in Investigations on Human Subjects" referred to the ethical problems and constraints associated with undertaking clinical research procedures on minors and mentally subnormal or disordered patients. In survey work few difficulties are likely to arise, but it is incumbent on research workers undertaking such work to inform patients, and relatives in the case of minors, about the nature of the inquiry and to seek the consent of relevant authorities to the survey.

\section{(5) Custody of Medical Records}

As a result of special research studies large collections of medical research data are being compiled, and it is desirable that access to such collections should be governed by common standards and practices which ensure the maintenance of confinentiality. The Council therefore advises that the following principles and procedures be adopted by personnel responsible for the custody of those records compiled during the course of medical research.

(i) Responsibility for the control of medical research records and information should be that of the director or leader of the research team involved in their collection. In those cases where the director is not medically qualified he should be advised either by a medically qualified collaborator or specially constituted medical committee. Should this not prove practicable, then the advice and approval of the Standing Committee (referred to in the appendix) should be sought regarding arrangements for the handling and control of such records.

(ii) All persons involved in the handling of such data should give a written undertaking to maintain confidentiality.

(iii) Appropriate arrangements should be made and enforced at all times for the adequate physical security of establishments where confidential medical information is stored and used. With regard to records themselves, consideration should be given to the use of special arrangements-for example, the separation and replacement by code of identifying data from the main body of the record and "scrambling" within computer systems.

(iv) Data of a general statistical nature (that is, in a form that prevents identification of individuals) may be made available to other research workers at the discretion of the director.

(v) In general, information obtained by a research worker is subject to the same restrictions as apply in clinical practice, where the patient's interests are paramount. Unless expressly forbidden by the individual to do so, the research worker should be willing to communicate relevant information to a clinician treating the patient. As far as release of information to other research workers is concerned, the custodian of research data should be guided by the principles of section 3.

(iv) Those responsible for collecting and storing personal medical data should review at intervals the desirability of destroying material when its retention is no longer essential.

\section{(6) In Conclusion}

This statement does not attempt to anticipate every situation that may arise in a rapidly developing field of medicine. The Council will review it in the light of experience obtained by research workers, clinicians, and committees. In this way the continued development and progress of medical research 
within the context of approved ethical standards and conduct of those concerned, and continued public trust, can be ensured.

\section{Reference}

1 Medical Research Council, "Responsibility in Investigations on Human Subjects," Annual Report for 1962-3, Cmnd. 2382, pp. 21-25. London. H.M.S.O., 1964. Republished in British Medical fournal, 1964, 2,178 .

\section{Appendix}

Standing Committee on the Use of Medical Information for Research

The Council has decided to set up a Standing Committee with the following terms of reference:

(i) to establish, interpret, and review provisions governing the collection, security, use of, and access to confidential medical research da+a in accordance with principles determined by the Council in its statement "Responsibility in the Use of Medical Information for R-search;" and to consider questions concerning interpretation of this statement.

(ii) in the light of these provisions, to advise its staff and others who receive grants or other support from it on questions on the use of or access to such confidential medical research data.

The committee, which will be responsible to the Council, will consist of a chairman, deputy chairman, and representatives of the public and the medical profession.

The Medical Research Council wishes to acknowledge the help and advice received from its Committee on General Epidemiology, which was responsible for drafting this statement. The members concerned were: Professor D. D. Reid (chairman), Dr. A. M. Adelstein, Professor E. D. Acheson, Professor E. A. Cheeseman, Professor A. L. Cochrane, Dr. M. A. Heasman, Professor W. W. Holland, Professor E. A. Smith, Dr. A. H. Snaith, Dr. P. A. Walford, Dr. J. M. G. Wilson, Professor J. K. Wing, Dr. M. Ashley-Miller (secretary), Dr. G. K. Matthew (observer). In addition the council received valuable assistance from the chief medical officers of the Health Departments, the British Medical Association, and the directors of certain of its own establishments.

\title{
Clinicopathological Conference
}

\section{Essential Malignant Hypertension with Renal Failure and Persistent Australia-antigenaemia}

\author{
DEMONSTRATED AT THE ROYAL POSTGRADUATE MEDICAL SCHOOL
}

ARRANGED BY PROFESSOR C. T. DOLLERY AND PROFESSOR C. V. HARRISON

British Medical fournal, 1973, 1, 216-223

PROFESSOR C. T. DOLLERY (1): This patient represents a general problem and a special problem. The general problem is less common nowadays because the treatment of hypertension has become more effective. At one time we had many patients with malignant hypertension dying in uraemia, and frequent conferences to discuss them. They are less common now because these patients are prevented from progressing into renal failure by earlier treatment. The special problem, around which much of today's discussion will orientate, is that he had a very strongly positive Australia antigen.

This patient was a Pole who had lived in this country for 20 years. He was 45 years old at death, and he first came to this hospital seven years ago to the renal outpatient department, where he was found to have mild hypertension $(160 / 100 \mathrm{~mm} \mathrm{Hg})$. At the time we were not taking so much notice of mild hypertension in young men-we would take more notice today. However, he had an intravenous pyelogram and it was normal; his blood urea level was slightly raised at $41 \mathrm{mg} / 100 \mathrm{ml}$. No treatment was recommended and the patient left to attend a chiropractor.

He was well for five years after that, but then attended gastroenterology outpatients, complaining of rather indefinite abdominal pain, with loss of appetite and weight loss of several pounds. His blood pressure was normal, but his liver function tests were abnormal: bilirubin normal at $0.6 \mathrm{mg} / 100$ $\mathrm{ml}$; alkaline phosphatase very slightly raised at 16KA units; isocitric dehydrogenase very high at 30 units (N 3-8) and the SGOT raised at 63 units $(\mathrm{N}<20)$. A diagnosis was made of anicteric hepatitis, and over the next few weeks the symptoms abated, the liver function tests returned to normal, and he was discharged.

Soon after this he developed gradually worsening frequency of urination at night and breathlessness on exertion. He had a small haemoptysis and came up to hospital in July 1970 looking ill. His blood pressure was $180 / 125$ and there was evidence of left ventricular failure with tachypnoea and basal crepitations in the lungs, and bilateral papilloedema with cottonwool spots and small haemorrhages. So he fulfilled the clinical criteria of malignant hypertension, and we would expect that if he had had a renal biopsy at that stage it would have shown fibrinoid necrosis and onion-skin proliferation in the arterioles.

We normally treat malignant hypertension as a medical emergency, usually with diazoxide-which is a vasodilator substance related in structure but not in pharmacology to chlorothiazide. With a dose of $300 \mathrm{mg}$ his blood pressure fell rapidly and he was then controlled on oral methyldopa, digitalis, and a diuretic. He came out of failure and his pressure was well controlled. Many investigations were done and I shall draw your attention to a few of the most important. Before treatment his blood urea was $53 \mathrm{mg} / 100 \mathrm{ml}$ and creatinine clearance $36 \mathrm{ml} / \mathrm{min}$; proteinuria was $9 \mathrm{~g} /$ per day and he had a low serum potassium of $2.7 \mathrm{mN}$. Hypokalaemia is common in accelerated hypertension, and these patients in the malignant 